\title{
Renewal of conditioned fear responses using a film clip as the aversive unconditioned stimulus
}

Citation for published version (APA):

Landkroon, E., Mertens, G., Sevenster, D., Dibbets, P., \& Engelhard, I. M. (2019). Renewal of conditioned fear responses using a film clip as the aversive unconditioned stimulus. Journal of Behavior Therapy and Experimental Psychiatry, 65, [101493]. https://doi.org/10.1016/j.jbtep.2019.101493

Document status and date:

Published: 01/12/2019

DOI:

10.1016/j.jbtep.2019.101493

Document Version:

Publisher's PDF, also known as Version of record

Document license:

Taverne

Please check the document version of this publication:

- A submitted manuscript is the version of the article upon submission and before peer-review. There can be important differences between the submitted version and the official published version of record.

People interested in the research are advised to contact the author for the final version of the publication, or visit the DOI to the publisher's website.

- The final author version and the galley proof are versions of the publication after peer review.

- The final published version features the final layout of the paper including the volume, issue and page numbers.

Link to publication

\footnotetext{
General rights rights.

- You may freely distribute the URL identifying the publication in the public portal. please follow below link for the End User Agreement:

www.umlib.nl/taverne-license

Take down policy

If you believe that this document breaches copyright please contact us at:

repository@maastrichtuniversity.nl

providing details and we will investigate your claim.
}

Copyright and moral rights for the publications made accessible in the public portal are retained by the authors and/or other copyright owners and it is a condition of accessing publications that users recognise and abide by the legal requirements associated with these

- Users may download and print one copy of any publication from the public portal for the purpose of private study or research.

- You may not further distribute the material or use it for any profit-making activity or commercial gain

If the publication is distributed under the terms of Article $25 \mathrm{fa}$ of the Dutch Copyright Act, indicated by the "Taverne" license above, 


\title{
Renewal of conditioned fear responses using a film clip as the aversive unconditioned stimulus
}

\author{
Elze Landkroon ${ }^{\mathrm{a}, *}$, Gaëtan Mertens ${ }^{\mathrm{a}}$, Dieuwke Sevenster ${ }^{\mathrm{a}}$, Pauline Dibbets ${ }^{\mathrm{b}}$, Iris M. Engelhard ${ }^{\mathrm{a}}$

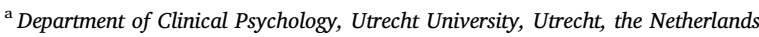 \\ ${ }^{\mathrm{b}}$ Department of Clinical Psychological Science, Maastricht University, the Netherlands
}

\section{A R T I C L E I N F O}

\section{Keywords:}

Renewal

Return of fear

Fear conditioning

Extinction

Aversive film clip

\begin{abstract}
A B S T R A C T
Background and objectives: Pavlovian fear conditioning paradigms are valuable to investigate fear learning and the return of extinguished fear in the lab. However, their validity is limited, because the aversive stimuli (e.g., electric shocks) typically lack the modalities and complexity of real-world aversive experiences. To overcome this limitation, we examined fear acquisition, extinction and contextual renewal using an audiovisual unconditioned stimulus (US).

Method: On day 1, 50 healthy participants completed an acquisition phase in a specific context (i.e., desk or bookcase, 'context A'). Pictures of colored lamps served as conditioned stimuli and an aversive film clip was used as US. On day 2, extinction took place in the same context ('context A') or in a different context ('context B'). Afterwards, renewal was tested in the acquisition context (AAA vs. ABA design).

Results: As hypothesized, fear acquisition and extinction, as measured by US expectancy ratings, fear potentiated startle (FPS), and skin conductance responses (SCRs), were successful. Most importantly, conditioned responding was renewed on all measures in the ABA condition, but not in the AAA condition. Differential renewal (i.e., larger renewal for CS + than for CS-) was only observed for US expectancy ratings.

Limitations: The return of conditioned responses was non-differential for FPS and SCR.

Conclusions: The current set-up enables investigation of fear renewal using an audiovisual US. Future studies can utilize this paradigm to investigate interventions that aim to reduce fear renewal by modifying the US memory, such as Eye Movement Desensitization and Reprocessing and imagery rescripting.
\end{abstract}

\section{Introduction}

Pavlovian fear conditioning paradigms are valuable to investigate fear learning and extinction in the lab (Vervliet, Craske, \& Hermans, 2013). In these paradigms, an initially neutral stimulus (conditioned stimulus; CS) is repeatedly paired with an aversive stimulus (unconditioned stimulus; US). This usually results in conditioned fear reactions to the CS (conditioned responses; CRs). Then, during extinction training, the CS is repeatedly presented without the US, which usually results in a reduction of fear responding to the CS. Studies examining these two phenomena have provided important insights into the etiology and treatment of anxiety disorders (e.g., Vervliet, Craske, et al., 2013).

Contemporary conditioning models argue that extinction learning results in the formation of a new, inhibitory association (CS-no US; Bouton, 2002). Hence, the original CS-US association remains intact, but is suppressed by the inhibitory CS-no US association. However, this latter association is vulnerable to context changes, and under certain circumstances the original threat association (CS-US) can become dominant again. For instance, a context change after extinction can facilitate the retrieval of the CS-US memory, and as a result, fear can return ('renewal'). In clinical practice, a switch from a therapy context to a non-therapy context could result in relapse of an extinguished fear response. Therefore, fear renewal poses a major limitation to current exposure-based treatments (Bouton, 2002; Vervliet, Craske, et al., 2013).

An alternative approach to reduce fear may be to modify the fear memory (e.g., Elsey, Van Ast, \& Kindt, 2018). There is increased recognition that anxiety patients' feared catastrophes (illness, attack, humiliation, death) often take the form of vivid mental images, not just verbal thoughts (Hackmann \& Holmes, 2004; Holmes \& Mathews, 2010). These are typically visual but may also occur in other sensory modalities (auditory, tactile; e.g., Ehlers et al., 2002; Engelhard, van den Hout, Arntz, \& McNally, 2002; Engelhard, van den Hout, Janssen, \&

\footnotetext{
${ }^{*}$ Corresponding author. Department of Clinical Psychology, Utrecht University, PO Box 80140, 3508 TC Utrecht, the Netherlands.

E-mail address: e.landkroon@uu.nl (E. Landkroon).
} 
van der Beek, 2010). The ability to imagine and reflect on experiences can not only evoke fear, but also opens up the opportunity for new ways of changing threat memories in humans. Imagery modification techniques are used in the treatment of posttraumatic stress disorder to target traumatic memories (e.g., Engelhard, McNally, \& van Schie, 2019; Morina, Lancee, \& Arntz, 2017), and they hold great promise for the treatment of other anxiety disorders. However, most conditioning experiments use electrical stimulation or white noise as US, even though these stimuli do not model the complexity and visual nature of fear memories outside the lab (Beckers, Krypotos, Boddez, Effting, \& Kindt, 2013; Scheveneels, Boddez, Vervliet, \& Hermans, 2016). Therefore, using more complex multimodal stimuli as US would improve the ecological validity of conditioning models and provide a paradigm to test whether psychological interventions that directly target emotional memory features, such as Eye Movement Desensitization and Reprocessing (EMDR; Engelhard et al., 2019) and imagery rescripting (Morina et al., 2017), can be used to attenuate renewal of fear.

Recently, several fear conditioning studies used an aversive film clip as US (e.g., Dibbets, Lemmens, \& Voncken, 2018; Kunze, Arntz, \& Kindt, 2015; Leer, Engelhard, Altink, \& van den Hout, 2013; Wegerer, Blechert, Kerschbaum, \& Wilhelm, 2013). These studies indicated that using such a stimulus can result in strong conditioned fear responses and these responses typically diminish after an extinction procedure. They also showed that unexpected presentation of the US after extinction results in fear reinstatement, indicating that this paradigm is suitable for examining the return of fear through this procedure (Dibbets et al., 2018; Kunze et al., 2015). However, they did not examine the return of extinguished fear after a change in external context ('context renewal'), even though this can be an important source for relapse (e.g., after a switch from the therapy to non-therapy context; Bouton, 2002; Vervliet, Craske, et al., 2013). The aim of the current study was to examine whether the context renewal effect occurs when the US is an aversive film clip. We adjusted an existing fear conditioning paradigm that is known to elicit renewal (Milad, Orr, Pitman, \& Rauch, 2005) by using an aversive film clip (Dibbets et al., 2018) instead of electrical shock as US. Participants underwent a two-day fear conditioning paradigm with acquisition on day 1 (context A) and extinction on day 2 (context A or B), followed by a test phase in the acquisition context. Based on previous results, we hypothesized that fear would be conditioned on day 1 and would be extinguished on day 2. Most importantly, we hypothesized that a switch in context after extinction would result in return of the conditioned fear response.

\section{Method}

\subsection{Pre-registration}

The design, procedure, hypotheses, data analyses, and sample size were pre-registered on the Open Science Framework prior to the data collection (https://osf.io/pzu7s/).

\subsection{Participants}

Fifty-one individuals participated in the study. One participant was excluded from the data analysis, because she fell asleep during the second session (condition AAA), resulting in a final sample of 50 participants (34 females, 16 males), with a mean age of 21.60 years ( $S D=2.13$ years). The sample consisted of 45 undergraduate students, 3 graduate students, and 2 non-students. Exclusion criteria were selfreported poor eyesight, color blindness, hearing difficulties, the use of medication that influenced attention and concentration, (a history of) mental problems, pregnancy and serious medical conditions (e.g., heart problems). Initially, 67 individuals were interested in participating in this study, but 16 individuals could not participate on the basis of these exclusion criteria. Thus, 51 participants started the study. Participants received course credit or a small financial compensation. All participants gave written informed consent. The Ethics Committee of the Faculty of Social Sciences of Utrecht University (FETC16-054) approved this study.

\subsection{Stimuli}

Contextual stimuli were two pictures that each showed a specific room with a desk or a bookcase (see Milad et al., 2005). In each of these contexts, the same lamp was present. CSs were colors (blue and yellow) of the lit lamp. Context and CS types were counterbalanced across participants. The US was a film clip $(6 \mathrm{~s})$ of a woman who carries a pan of boiling water in a kitchen, slips, and falls, while spilling the water on her face (see Dibbets et al., 2018). At the end of the film clip, the woman has visible burns on her face and screams loudly (volume peak: $95 \mathrm{~dB}$; https://www.youtube.com/watch? $\mathrm{v}=\mathrm{tN} 2 \mathrm{gpRcFKAQ}$ ). The clip was an ad from the workplace health and safety marketing campaign from Ontario's workers' compensation board. Earlier research showed that participants do not habituate to this US, but sensitize over trials (Dibbets et al., 2018).

\subsection{Questionnaires}

The State-Trait Anxiety Inventory (STAI-DY; Spielberger, Gorsuch, Lushene, Vagg, \& Jacobs, 1983) was used to assess state (STAI-S) and trait anxiety (STAI-T). It was included to examine whether anxiety levels were similar between conditions, because anxiety levels may influence fear learning (e.g., Duits et al., 2015; Lommen, Engelhard, \& van den Hout, 2010; Lonsdorf \& Merz, 2017; but see, e.g., TorrentsRodas et al., 2013).

\subsection{Outcome measures}

\subsubsection{US expectancy}

Participants rated US expectancy during each CS presentation (within $7 \mathrm{~s}$ after CS onset) on a visual analogue scale (VAS) at the bottom of the computer screen ('Do you expect the aversive film clip to follow?') ranging from -5 ( = definitely not) to 5 (= definitely), with 0 (= uncertain) as midpoint.

\subsubsection{Fear potentiated startle (FPS)}

Psychophysiological responses were measured with the BioSemi ActiveTwo system, recorded with the software program Actiview, and analyzed with BrainVision Analyzer. FPS was measured with electromyography (EMG) of the left orbicularis oculi muscle with two $4 \mathrm{~mm}$ $\mathrm{Ag} / \mathrm{AgCl}$ electrodes. One electrode was positioned approximately $1 \mathrm{~cm}$ below the pupil and the other electrode was positioned $1 \mathrm{~cm}$ below the lateral canthus. Two ground electrodes were attached on the forehead. Startle probes $(50 \mathrm{~ms} ; 105 \mathrm{~dB})$ were administered through Sennheiser HD201 headphones. According to published guidelines, the data were filtered $(28-500 \mathrm{~Hz})$, rectified, and filtered again $(14 \mathrm{~Hz})$ for smoothing (Blumenthal et al., 2005). The peak amplitude was determined in 20-150 ms following probe onset and was baseline corrected (i.e., peak amplitude minus the mean amplitude between $30 \mathrm{~ms}$ before to $20 \mathrm{~ms}$ after probe onset).

\subsubsection{Skin conductance response (SCR)}

Two $5 \mathrm{~mm} \mathrm{Ag} / \mathrm{AgCl}$ electrodes were attached to the proximal part of the palm of the left hand. Electrodes were attached approximately $1.5 \mathrm{~cm}$ apart. According to published guidelines, data were filtered (lowpass filter: $10 \mathrm{~Hz}$; notch filter: $50 \mathrm{~Hz}$; Boucsein et al., 2012). Entire interval responses were calculated by subtracting the mean baseline $(2 \mathrm{~s}$ before CS onset) from the highest amplitude in 1-7s after CS onset (Pineles, Orr, \& Orr, 2009). 


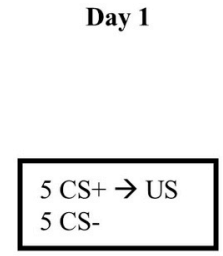

Acquisition
Day 2

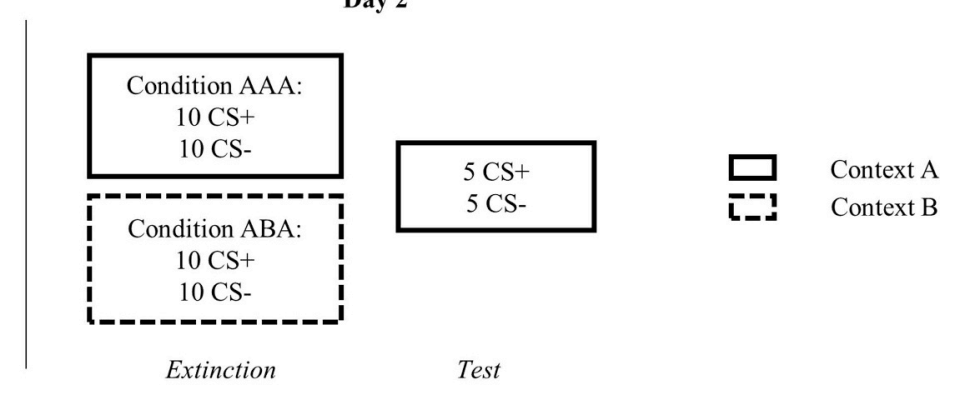

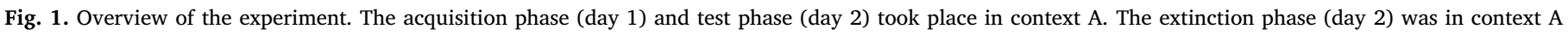
$(n=25)$ or $\mathrm{B}(n=25)$.

\subsection{Procedure}

The acquisition and extinction phases were on two separate days to ensure consolidation of acquisition memory into long-term memory (McGaugh, 2000; Nader, 2003). The extinction phase was immediately followed by the test phase (see Fig. 1). Both testing sessions took approximately $45 \mathrm{~min}$.

\subsubsection{Acquisition phase - day 1}

After participants gave written informed consent, they completed the STAI and screening questionnaire to ensure they had not used drugs or alcohol prior to the session. Next, electrodes were attached, and headphones were put on. Participants then read instructions on the computer screen. First, they were informed that the woman in the film clip was a sous-chef in a restaurant who would get promoted next year and would get married the following weekend. This information was provided to create context for the US (following Dibbets et al., 2018). Then, participants viewed a 10 -s version of the aversive film clip (95 dB). Next, they were instructed about the CS-US contingency (following Milad et al., 2005). Ten habituation probes were used to stabilize startle reactivity. Then the acquisition phase followed, in which participants were presented each of the two CSs five times in a random order, but with no more than two consecutive presentations of the same CS. In each trial in the acquisition phase, the context picture (desk or bookcase) was presented for $14 \mathrm{~s}$. Six seconds after context onset, the CS (i.e., lamp light on) was presented for $8 \mathrm{~s}$ within the context (as in Milad et al., 2005). Seven seconds after CS onset, the startle probe was presented. The US was presented at CS + offset $(100 \%$ reinforcement rate). Intertrial interval (ITI) was 10,12 , or $14 \mathrm{~s}$ and consisted of a black screen. In half of the trials, a probe was presented during the ITI and ITI duration was doubled $(20,24$, or $28 \mathrm{~s})$.

\subsubsection{Extinction and test phases - day 2}

Participants entered the lab $24 \mathrm{~h}$ after the first testing day. Again, electrodes were attached. Participants were instructed to think back to what they had learned on the previous day (following Milad et al., 2005). Then, they received 10 habituation startle probes, followed by the extinction phase that consisted of 10 presentations of each CS in the acquisition context (condition AAA) or a new context (condition ABA). The test phase followed, in which each CS was presented five times in the acquisition context. The first CS presentation in the extinction and test phases was counterbalanced. In each phase, CS presentation was again semi-random, and timing of the trials was identical to that of day 1. Finally, electrodes were removed, and participants indicated how aversive they found the film clip on a VAS ranging from 0 ( $=$ not at all) to 100 (= definitely).

\subsection{Data analyses}

\subsubsection{Data preparation}

The SCR data was range corrected to reduce individual variation and transformed with a log-transformation to reduce the skewedness of the distribution (Boucsein et al., 2012). A minimal response value of $0.02 \mu \mathrm{S}$ was applied. ${ }^{1}$ The FPS data was t-transformed to reduce individual variation (Blumenthal et al., 2005). For one participant, FPS data was missing on both days due to technical difficulties (ABA condition), and for one participant physiological data was missing on day 2 (ABA condition). The available data of these two participants are included in the data analyses. The alpha level was 0.05 for all analyses. Cohen's d was used as measure of effect size for t-tests. When the assumption of sphericity was violated, degrees of freedom were corrected with Greenhouse-Geisser $(\varepsilon<0.75)$ or Huyn-Feldt $(\varepsilon>0.75)$.

\subsubsection{Randomization check}

STAI-S, STAI-T, and US aversiveness were compared to check for group differences on these measures using independent-samples t-tests.

\subsubsection{Acquisition and extinction phase}

The acquisition and extinction phases were analyzed with a 2 (Stimulus: CS + vs. CS-) x 5 or 10 (Trial) repeated measures ANOVA on all outcome measures. The factor Condition (AAA vs. ABA) was added to investigate differences between conditions.

\subsubsection{Renewal}

Renewal was tested with a 2 (Stimulus; CS + vs. CS-) x 2 (Trial; last extinction trial vs. first test trial) $\mathrm{x} 2$ (Condition; AAA vs. ABA) interaction (Vervliet, Baeyens, Van den Bergh, \& Hermans, 2013). Separate analyses followed significant interactions.

\section{Results}

There were no differences between the conditions in STAI-S, STAI-T, and rated aversiveness of the film clip (Table 1).

\footnotetext{
${ }^{1}$ We explored if the quality improved by excluding participants who had an excessive number of zero and missing responses in their psychophysiological data (e.g., Sehlmeyer et al., 2009). Eight participants had to be excluded when participants with excessive zero and missing responses (more than $80 \%$ of the trials) on SCR were removed ( $n=3$ in ABA group, $n=5$ in AAA group). The main effect of CS during the acquisition phase showed a trend $(p=.06$, $\eta_{p}{ }^{2}=0.09$ ) and the three-way interaction between stimulus $\mathrm{x}$ trial $\mathrm{x}$ condition was significant $\left(p=.02, \eta_{p}{ }^{2}=0.07\right)$. These differences in results are probably due to a decrease in power. All other results on SCR in extinction and renewal remained the same. Therefore, we decided to report the analyses on the full sample.
} 
Table 1

Means (SD) of state anxiety (STAI-S), trait anxiety (STAI-T), and US aversiveness for AAA $(n=25)$ and ABA $(n=25)$ conditions.

\begin{tabular}{llllll}
\hline & AAA & ABA & $t(48)$ & $p$ & $d$ \\
\hline STAI-S & $34.04(6.56)$ & $33.28(4.21)$ & 0.49 & .63 & 0.14 \\
STAI-T & $34.88(7.10)$ & $37.32(9.37)$ & 1.04 & .31 & 0.29 \\
US aversiveness & $68.44(18.93)$ & $68.84(22.90)$ & 0.07 & .95 & 0.02 \\
\hline
\end{tabular}

\subsection{US expectancy ratings}

\subsubsection{Acquisition}

On day 1, acquisition of US expectancy was evidenced by a significant increase in differential responding between CS + and CS- over the 5 acquisition trials, $F(2.30,112.47)=80.31, p<.01, \eta_{p}{ }^{2}=0.62$ (stimulus $\mathrm{x}$ trial), see Fig. 2. The conditions did not differ in acquisition of US expectancy, $F(2.29,109.85)=0.45, p=.67, \eta_{p}{ }^{2}=0.01$ (stimulus $\mathrm{x}$ trial $\mathrm{x}$ condition). All participants were aware of the contingencies at the end of the acquisition phase (US expectancy difference CS + vs. CS- $\geq 6.90$ ).

\subsubsection{Extinction}

Extinction of US expectancy ratings was demonstrated by a decrease in differential US expectancy ratings (CS + vs. CS-) over the course of extinction trials, $F(3.35,163.97)=39.40, p<.01, \eta_{p}{ }^{2}=0.45$ (stimulus $\mathrm{x}$ trial). At the first extinction trial, ratings for the CS + were higher than for the CS-, $t(49)=9.55, p<.01, d=1.35$, while the scores did not differ at the last extinction trial, $t(49)=0.90, p=.37$, $d=0.13$. There was no difference in extinction learning between the conditions, $F(3.35,160.73)=1.14, p=.34, \eta_{p}{ }^{2}=0.02$ (stimulus $\mathrm{x}$ trial $\mathrm{x}$ condition).

\subsubsection{Renewal}

There was a difference between the conditions in US expectancy ratings (CS + vs. CS-) from the last trial of extinction to the first test trial, $F(1,48)=15.87, p<.01, \eta_{p}{ }^{2}=0.25$ (stimulus $\mathrm{x}$ trial $\mathrm{x}$ condition). In line with our expectations, differential US expectancy increased for the ABA condition from the last trial of extinction to the first test trial, $F(1,24)=15.97, p<.01, \eta_{p}{ }^{2}=0.40$ (stimulus $\mathrm{x}$ trial). In contrast, renewal was not observed in condition AAA, $F(1,24)=0.20$, $p=.66, \eta_{p}{ }^{2}=0.01$ (stimulus $\mathrm{x}$ trial). In the ABA group, there was no difference between CS + and CS- ratings at the end of extinction, $t$ $(24)=0.48, p=.64, d=0.10$, while ratings were higher for the $\mathrm{CS}+$ than CS- at the first test trial, $t(24)=3.70, p<.01, d=0.74$. In the AAA group, CS + and CS- ratings did not differ at the end of extinction, $t(24)=1.12, p=.28, d=0.16$, or the first test trial, $t$ $(24)=0.89, p=.39, d=0.18$. In summary, these results indicate a greater return of US expectancy for the threatening stimulus (CS+) compared to the control stimulus (CS-) in the ABA condition, but not in the AAA condition.
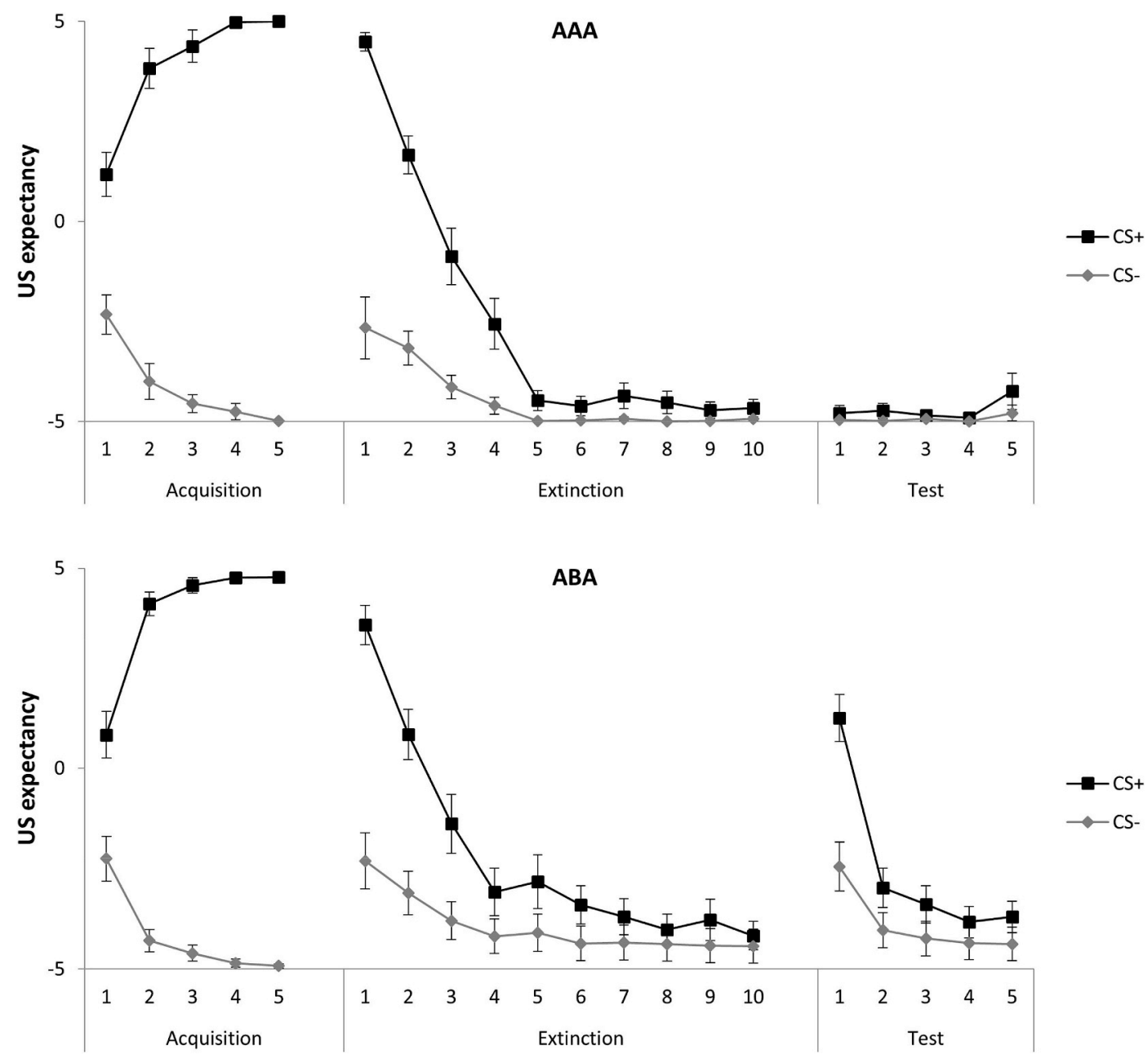

ABA

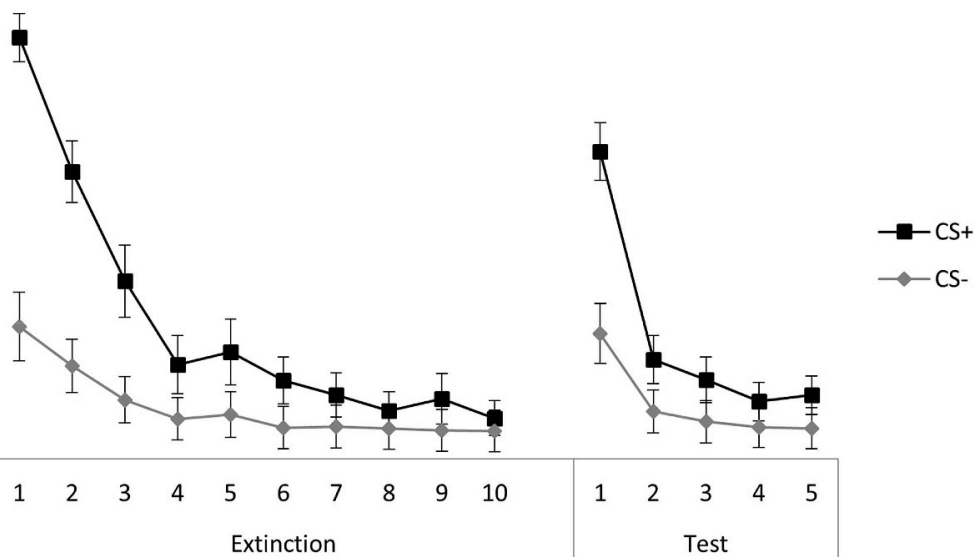

Fig. 2. US expectancy on acquisition, extinction, and test phase of the experiment in the AAA $(n=25)$ and ABA $(n=25)$ conditions. Error bars represent standard error of the mean (SEM). 

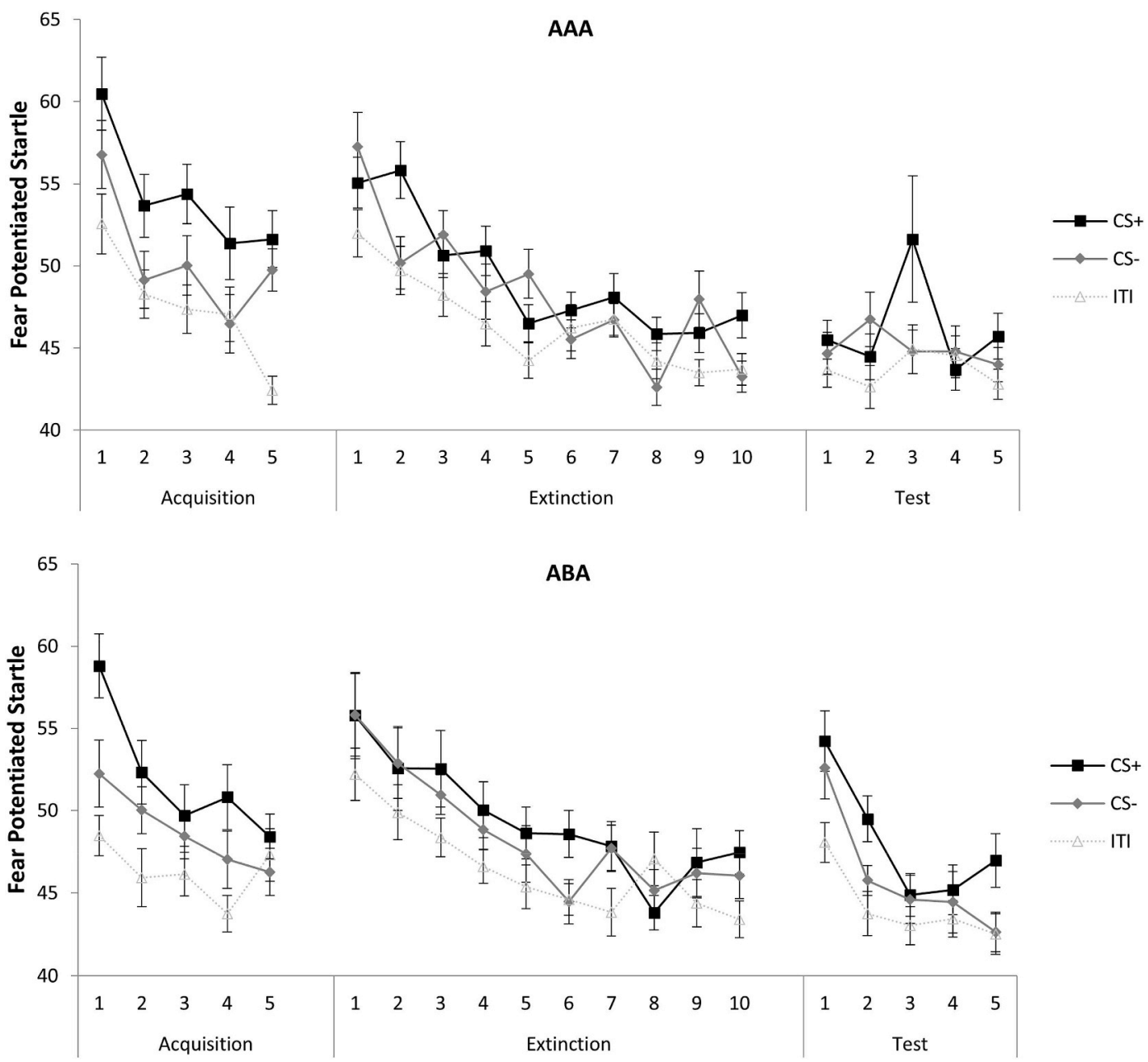

Fig. 3. Fear potentiated startle response on acquisition, extinction, and test phase of the experiment in AAA $(n=25)$ and ABA ( $n=24)$ conditions. Error bars represent SEM.

\subsection{Fear potentiated startle}

\subsubsection{Acquisition $^{2} 3$}

There was no differential increase over the 5 acquisition trials, $F(8$, $384)=0.71, p=.69, \eta_{p}{ }^{2}=0.01$ (stimulus $\mathrm{x}$ trial), but we did observe a main effect of stimulus, $F(2,96)=31.85, p<.01, \eta_{p}{ }^{2}=0.40$, see Fig. 3. The mean score for CS+ $(M=53.18, S D=5.31)$ was higher than the mean CS- score $(M=49.63, S D=4.74), t(48)=4.19$, $p<.01, d=0.60$, and the mean ITI score $(M=46.94, S D=3.18), t$ (48) $=7.37, p<.01, d=1.05$. The mean CS- score was higher than

\footnotetext{
${ }^{2}$ We have visually inspected all FPS data. When we classified responses that showed artefacts as missing ( $3.7 \%$ of all values) and classified non-responses as zero (5.1\% of all values), the graphs and data analyses did not differ from the analyses on the full sample. We also used an alternative approach to classify non-responses as smaller than twice the baseline amplitude (11\% of all values). With this approach, the graphs and data analyses again did not differ from the analyses on the full sample. However, because missing data are problematic for ANOVAs (i.e., due to listwise exclusion), we decided to report the data analyses on the full dataset (these alternative analyses and graphs are included in the supplementary results).

${ }^{3}$ We have also analyzed the data separately for individuals that displayed differential acquisition on the psychophysiology measures (higher $\mathrm{CS}+$ responding than CS- responding on the last acquisition trial). The graphs and data analyses remained mostly the same to the analyses on the full sample (these additional analyses and graphs on both FPS and SCR are included in the supplementary results).
}

the mean ITI score, $t(48)=4.20, p<.01, d=0.60$. A significant main effect of CS indicates successful acquisition (i.e., larger startle responses for CS + than CS-). The conditions did not differ in acquisition of startle responses, $F(8,376)=1.76, p=.08, \eta_{p}{ }^{2}=0.04$ (stimulus $\mathrm{x}$ trial $\mathrm{x}$ condition) and $F(2,94)=0.24, p=.79, \eta_{p}{ }^{2}=0.01$ (stimulus $\mathrm{x}$ condition).

\subsubsection{Extinction}

The interaction between stimulus and trial was not significant, $F$ $(11.71,550.23)=1.38, p=.18, \eta_{p}{ }^{2}=0.03$. Startle responses decreased over time, $F(5.72,269.02)=28.29, p<.01, \eta_{p}{ }^{2}=0.38$ (main effect trial). There was also a main effect of stimulus, $F(2,94)=16.99$, $p<.01, \eta_{p}{ }^{2}=0.27$. The mean score for the CS $+(M=49.25$, $S D=2.68)$ was higher than the CS- mean score $(M=48.17$, $S D=3.36), t(48)=2.28, p=.03, d=0.33$, and both the mean $\mathrm{CS}+$ score and the mean CS- score were higher than the mean ITI score $(M=46.55, \quad S D=2.32), \quad t(48)=5.14, \quad p<.01, d=0.73$ and $t$ (48) $=2.73, p<.01, d=0.39$ respectively. Conditions did not differ in extinction, $F(11.51,529.43)=0.97, p=.48, \eta_{p}{ }^{2}=0.02$ (stimulus $\mathrm{x}$ trial $\mathrm{x}$ condition) and $F(2,92)=0.02, p=.98, \eta_{p}{ }^{2}=0.00$ (stimulus $\mathrm{x}$ condition).

\subsubsection{Renewal}

There was no evidence for a specific renewal effect, $F(1.82$, 83.91) $=0.75, p=.46, \eta_{p}{ }^{2}=0.02$ (stimulus $\mathrm{x}$ trial $\mathrm{x}$ condition), but the conditions differed in responding over trials, $F(1,46)=12.23$, $p<.01, \eta_{p}{ }^{2}=0.21$ (trial $\mathrm{x}$ condition). Analyses for each condition 
separately showed a non-differential renewal effect. That is, in the ABA condition, there was a return of startle responding from the last extinction trial to the first test trial, $F(1,22)=16.59, p<.01, \eta_{p}{ }^{2}=0.43$ (main effect trial). In contrast, the AAA condition showed no return of startle responding, $F(1,24)=0.00, p=.96, \eta_{p}{ }^{2}=0.00$ (main effect trial). This implies that the return of non-differential startle responses in the ABA condition was due to the context switch and not to the passage of time.

\subsection{Skin conductance response}

\subsubsection{Acquisition}

There was no differential increase over the 5 trials of acquisition, $F$ $(4,196)=0.21, p=.93, \eta_{p}{ }^{2}=0.00$ (stimulus $\mathrm{x}$ trial), but there was overall higher responding to the CS + compared to the CS-, $F(1$, 49) $=7.34, p<.01, \eta_{p}{ }^{2}=0.13$ (main effect stimulus), see Fig. 4. This indicates successful acquisition. This was similar across conditions, $F(4$, 192 ) $=2.23, p=.07, \eta_{p}{ }^{2}=0.04$ (stimulus $\mathrm{x}$ trial $\mathrm{x}$ condition) and $F(1$, 48) $=0.00, p=.97, \eta_{p}{ }^{2}=0.00$ (stimulus $\mathrm{x}$ condition).

\subsubsection{Extinction}

Similar to results for FPS, the interaction between stimulus and trial was not significant, $F(6.63,318.13)=0.71, p=.65, \eta_{p}{ }^{2}=0.02$. SCRs to both the CS + and CS- decreased over time, $F(8.01,384.62)=4.18$, $p<.01, \eta_{p}{ }^{2}=0.08$ (main effect trial), but SCR was overall higher for the CS + than CS-, $F(1,48)=9.00, p<.01, \eta_{p}{ }^{2}=0.16$ (main effect stimulus). The conditions did not differ in extinction, $F(6.61$,
310.82) $=1.29, p=.26, \eta_{p}{ }^{2}=0.03$ (stimulus $\mathrm{x}$ trial $\mathrm{x}$ condition) and $F$ $(1,47)=0.91, p=.35, \eta_{p}^{2}=0.02$ (stimulus $\mathrm{x}$ condition).

\subsubsection{Renewal}

There was no overall renewal effect, $F(1,47)=0.13, p=.72$, $\eta_{p}{ }^{2}=0.00$ (stimulus $\mathrm{x}$ trial $\mathrm{x}$ condition), but conditions differed in responding over trials (last trial of extinction to first test trial), $F(1$, $47)=8.41, p<.01, \eta_{p}{ }^{2}=0.15$ (trial $\mathrm{x}$ condition). Analyses for each condition separately showed a renewal effect. In the ABA condition, there was a return of SCR from the last extinction trial to the first test trial, $F(1,23)=8.34, p<.01, \eta_{p}{ }^{2}=0.27$ (main effect trial). In contrast, in the AAA condition, there was no return of SCR, $F(1,24)=0.41$, $p=.53, \eta_{p}{ }^{2}=0.02$ (main effect trial). Therefore, the context switch resulted in a non-differential return of SCR in the ABA condition only. However, in the AAA condition there was overall higher responding to the CS + than to the CS- in SCR, $F(1,24)=8.13, p<.01, \eta_{p}{ }^{2}=0.25$ (main effect stimulus), suggesting that SCR to the CS + was not entirely extinguished.

\section{Discussion}

Taken together, our study demonstrates that conditioned acquisition, extinction, and, crucially, renewal of conditioned responses can be achieved using an audiovisual US (i.e., aversive film clip). The main finding was that in the $\mathrm{ABA}$ condition, a return to the original acquisition context after extinction resulted in a return of conditioned responses, whereas in the AAA condition (in which there was no context
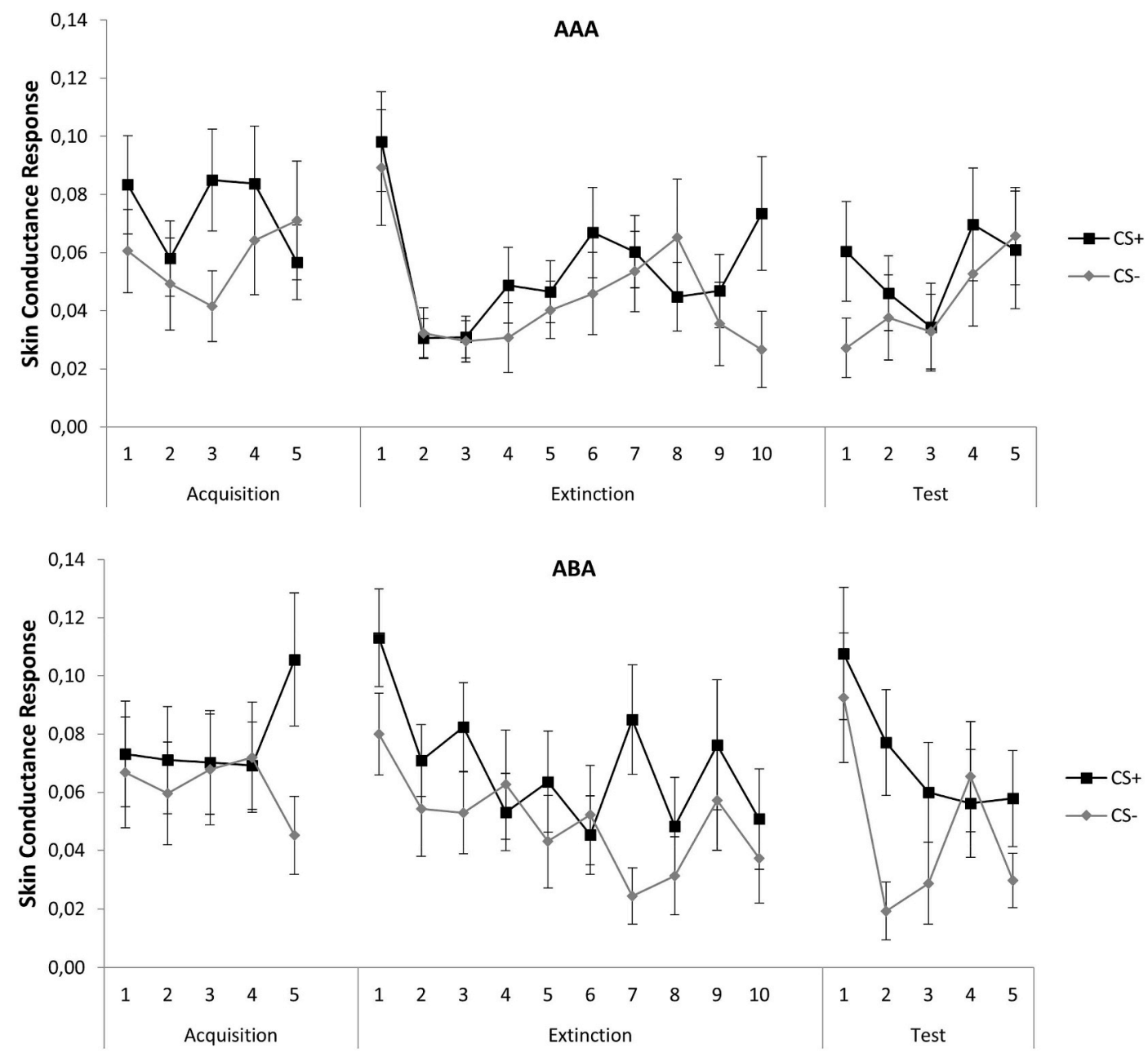

Fig. 4. Skin conductance response (SCR) on acquisition, extinction, and test phase during CS presentation in AAA $(n=25)$ and ABA $(n=25)$ conditions. Error bars represent SEM. 
switch after extinction) conditioned responses remained low. Higher conditioned responses in the ABA condition were evidenced by increased US expectancy ratings, FPS, and SCR, thereby confirming our hypothesis with different response systems. However, the crucial test for renewal should consider the interaction between condition, time, and stimulus type (Vervliet, Baeyens, et al., 2013). In the current study, only an increase in differential responding for the US expectancy ratings was identified, while for FPS and SCR the increase in the ABA condition was non-differential. This demonstrates that conditioned responses for both threat and safety stimuli were increased in the ABA condition. Therefore, the return of conditioned responses was not only due to the $\mathrm{CS}+$, but also due to general context effects that elevated fear in general (Vervliet, Baeyens, et al., 2013).

Findings for acquisition and extinction of conditioned responses are consistent with previous studies demonstrating that audiovisual stimuli can be used as US in conditioning paradigms (Dibbets et al., 2018; Kunze et al., 2015; Leer, Engelhard, Altink, et al., 2013; Wegerer et al., 2013), and extends earlier studies by showing that it can be used to study the context renewal effect. Using an audiovisual US instead of electrical stimulation can improve the external validity of conditioning models (Scheveneels et al., 2016).

The fact that we were able to observe renewal of conditioned responses with our paradigm opens up an important area of investigation. As mentioned previously, an important challenge for exposure and other therapies is to counter relapse after successful therapy. This may require a change of patients' aversive (and appetitive) memories (e.g., Elsey et al., 2018). Such memories can represent vivid mental images of past or future threat events (e.g., see Engelhard et al., 2010; Hackmann \& Holmes, 2004; Holmes \& Mathews, 2010). Our renewal paradigm can be utilized to investigate whether mental-imagery based interventions that weaken such memories, such as EMDR therapy (e.g., Engelhard et al., 2019) and imagery rescripting (Morina et al., 2017), can counter renewal of conditioned responses.

Several limitations of our study should be acknowledged. First, acquisition was not as clearly visible for the psychophysiological measures as it was for US expectancy. Acquisition on SCR and FPS was only evidenced by a main effect of stimulus type instead of an interaction between time and stimulus. Several explanations can account for this difference. First, this observation could be explained by the fact that participants were instructed beforehand that only one CS would be followed by a US (e.g., Dawson \& Biferno, 1973; Mertens et al., 2016). After the first trial of acquisition, differential responding to stimulus type was immediately present, which could account for the absence of an interaction effect. Indeed, this pattern during acquisition has been found in previous studies with comparable instructions (e.g., Leer, Engelhard, Dibbets, \& Van den Hout, 2013; Wegerer et al., 2013). Another possibility is that not all outcome variables measure the same construct. For instance, it is suggested that SCR and FPS measure arousal and fear respectively (e.g., Boucsein et al., 2012; Kindt \& Soeter, 2013), while US expectancy measures contingency awareness (Soeter \& Kindt, 2010). However, other researchers have argued that these different measures form an integrated response (Fanselow \& Pennington, 2018). This is further evidenced by the substantial correlations between the outcome measures (Dawson \& Furedy, 1976; Mertens et al., 2018; Sjouwerman, Scharfenort, \& Lonsdorf, 2017). The absence of strong acquisition for the psychophysiological measures may reflect the lower reliability of these measures (Ney et al., 2018), rather than them reflecting different constructs (for a similar argument in the context of different memory systems see Shanks \& Berry, 2012). Another interpretation for the absence of clear differential conditioning on the psychophysiological measures is that an audiovisual US may not be robust to induce differential conditioning on these measures. One study demonstrated that not all USs are equally effective to induce differential fear learning. Startle responses to a conditioning task with a shock were larger than to a scream (Glenn, Lieberman, \& Hajcak, 2012). However, other studies suggest that an unpleasant sound was equally effective to an aversive shock to produce differential fear conditioning (Neumann \& Waters, 2006) or even more effective (Sperl, Panitz, Hermann, \& Mueller, 2016). The possibility exists that our audiovisual US was not as effective as an aversive shock. A direct comparison between the USs is warranted to draw further conclusions on this matter.

A second limitation of the study is that the return of conditioned responses on SCR and FPS was non-differential (i.e., evident for both the threat and safety stimuli). It seems that for the ABA condition, both the CS and contextual cues became associated with the US. It is possible that participants in this condition interpreted contextual cues as a CS, because the context was not presented during ITIs (see Milad et al., 2005). Therefore, return to the original context might have increased arousal in general (see increases in ITI startle responses in Fig. 3). We suggest that future studies replace the black screen during the ITI with the context picture. Nonetheless, previous research has demonstrated that non-differential return of conditioned responses is not uncommon, even in procedures not involving a context switch (i.e., reinstatement; Haaker, Golkar, Hermans, \& Lonsdorf, 2014). Furthermore, in our study, the return of conditioned responses was differential on US expectancy, which is a valid measure for understanding fear (Boddez et al., 2013). Finally, many participants were non-responders on SCR. When they were excluded from the analyses, the acquisition on SCR showed only a trend towards higher CS + responding than CS-, which might be due to reduced statistical power. Also, without non-responders the two conditions differed in acquisition on SCR, indicating that acquisition on SCR was suboptimal. Even though acquisition differed between conditions when participants with an excessive number of non-responses were excluded, the results on extinction and renewal remained the same. This indicates that a context switch following extinction did renew conditioned responses on SCR.

In conclusion, this study demonstrates return of fear after conditioning with an aversive film clip. Building on earlier work by Milad et al. (2005) and Dibbets et al. (2018), we validated a conditioning paradigm with an audiovisual US to study renewal of conditioned responding. A return of conditioned responses was demonstrated upon a context switch after the extinction phase on both subjective and physiological measures. Future studies may use this paradigm to investigate whether interventions that aim to modify vivid emotional memories can be used to attenuate fear renewal.

\section{Conflicts of interest}

The authors declare no conflict of interest.

\section{Acknowledgements}

This study was funded by a VICI grant (grant number: 453-15-005) awarded to Iris M. Engelhard by the Netherlands Organization for Scientific Research (NWO). We thank Mohammed R. Milad for sharing the stimuli and Elise Both, Daan Klop, Jamie Lensen, Quno Post, and Denise Retera for help with the data collection.

\section{Appendix A. Supplementary data}

Supplementary data to this article can be found online at https:// doi.org/10.1016/j.jbtep.2019.101493.

\section{References}

Beckers, T., Krypotos, A. M., Boddez, Y., Effting, M., \& Kindt, M. (2013). What's wrong with fear conditioning? Biological Psychology, 92(1), 90-96. https://doi.org/10.1016/ j.biopsycho.2011.12.015.

Blumenthal, T. D., Cuthbert, B. N., Filion, D. L., Hackley, S., Lipp, O. V., \& Van Boxtel, A. (2005). Committee report: Guidelines for human startle eyeblink electromyographic studies. Psychophysiology, 42(1), 1-15. https://doi.org/10.1111/j.1469-8986.2005. 00271.x.

Boddez, Y., Baeyens, F., Luyten, L., Vansteenwegen, D., Hermans, D., \& Beckers, T. 
(2013). Rating data are underrated: Validity of US expectancy in human fear conditioning. Journal of Behavior Therapy and Experimental Psychiatry, 44(2), 201-206. https://doi.org/10.1016/j.jbtep.2012.08.003.

Boucsein, W., Fowles, D. C., Grimnes, S., Ben-Shakhar, G., Roth, W. T., Dawson, M. E. et al. (2012). Publication recommendations for electrodermal measurements. Psychophysiology, 49(8), 1017-1034. https://doi.org/10.1111/j.1469-8986.2012. 01384.x.

Bouton, M. E. (2002). Context, ambiguity, and unlearning: Sources of relapse after behavioral extinction. Biological Psychiatry, 52(10), 976-986. https://doi.org/10.1016/ S0006-3223(02)01546-9.

Dawson, M. E., \& Biferno, M. A. (1973). Concurrent measurement of awareness and electrodermal classical conditioning. Journal of Experimental Psychology, 101(1), 55-62. https://doi.org/10.1037/h0035524.

Dawson, M. E., \& Furedy, J. J. (1976). The role of awareness in human differential autonomic classical conditioning: The necessary-gate hypothesis. Psychophysiology, 13(1), 50-53. https://doi.org/10.1111/j.1469-8986.1976.tb03336.x.

Dibbets, P., Lemmens, A., \& Voncken, M. (2018). Turning negative memories around: Contingency versus devaluation techniques. Journal of Behavior Therapy and Experimental Psychiatry, 60, 5-12. https://doi.org/10.1016/j.jbtep.2018.02.001.

Duits, P., Cath, D. C., Lissek, S., Hox, J. J., Hamm, A. O., Engelhard, I. M., \& J.M.P. (2015). Updated meta-analysis of classical fear conditioning in the anxiety disorders. Depression and Anxiety, 32(4), 239-253. https://doi.org/10.1002/da.22353.

Ehlers, A., Hackmann, A., Steil, R., Clohessy, S., Wenninger, K., \& Winter, H. (2002). The nature of intrusive memories after trauma: The warning signal hypothesis. Behaviour Research and Therapy, 40(9), 995-1002. https://doi.org/10.1016/S0005-7967(01) 00077-8.

Elsey, J. W. B., Van Ast, V. A., \& Kindt, M. (2018). Human memory reconsolidation: A guiding framework and critical review of the evidence. Psychological Bulletin, 144(8), 797-848. https://doi.org/10.1037/bul0000152.

Engelhard, I. M., McNally, R. J., \& van Schie, K. (2019). Retrieving and modifying traumatic memories: Recent research relevant to three controversies. Current Directions in Psychological Science, 28(1), 91-96. https://doi.org/10.1177/ 0963721418807728.

Engelhard, I. M., van den Hout, M. A., Arntz, A., \& McNally, R. J. (2002). A longitudinal study of "intrusion-based reasoning" and posttraumatic stress disorder after exposure to a train disaster. Behaviour Research and Therapy, 40(12), 1415-1424. https://doi. org/10.1016/S0005-7967(02)00018-9.

Engelhard, I. M., van den Hout, M. A., Janssen, W. C., \& van der Beek, J. (2010). Eye movements reduce vividness and emotionality of "flashforwards. Behaviour Research and Therapy, 48(5), 442-447. https://doi.org/10.1016/j.brat.2010.01.003.

Fanselow, M. S., \& Pennington, Z. T. (2018). A return to the psychiatric dark ages with a two-system framework for fear. Behaviour Research and Therapy, 100, 24-29. August 2017 https://doi.org/10.1016/j.brat.2017.10.012.

Glenn, C. R., Lieberman, L., \& Hajcak, G. (2012). Comparing electric shock and a fearful screaming face as unconditioned stimuli for fear learning. International Journal of Psychophysiology, 86(3), 214-219. https://doi.org/10.1016/j.ijpsycho.2012.09.006.

Haaker, J., Golkar, A., Hermans, D., \& Lonsdorf, T. B. (2014). A review on human reinstatement studies: An overview and methodological challenges. Learning \& Memory, 21(9), 424-440. https://doi.org/10.1101/lm.036053.114.

Hackmann, A., \& Holmes, E. A. (2004). Reflecting on imagery: A clinical perspective and overview of the special issue of memory on mental imagery and memory in psychopathology. Memory, 12(4), 389-402. https://doi.org/10.1080/ 09658210444000133.

Holmes, E. A., \& Mathews, A. (2010). Mental imagery in emotion and emotional disorders. Clinical Psychology Review, 30(3), 349-362. https://doi.org/10.1016/j.cpr. 2010.01.001.

Kindt, M., \& Soeter, M. (2013). Reconsolidation in a human fear conditioning study: A test of extinction as updating mechanism. Biological Psychology, 92(1), 43-50. https://doi. org/10.1016/j.biopsycho.2011.09.016.

Kunze, A. E., Arntz, A., \& Kindt, M. (2015). Fear conditioning with film clips: A complex associative learning paradigm. Journal of Behavior Therapy and Experimental Psychiatry, 47, 42-50. https://doi.org/10.1016/j.jbtep.2014.11.007.

Leer, A., Engelhard, I. M., Altink, A., \& van den Hout, M. A. (2013). Eye movements during recall of aversive memory decreases conditioned fear. Behaviour Research and Therapy, 51(10), 633-640. https://doi.org/10.1016/j.brat.2013.07.004.

Leer, A., Engelhard, I. M., Dibbets, P., \& Van den Hout, M. (2013). Dual-tasking attenuates the return of fear after extinction. Journal of Experimental Psychopathology, 4(4), 325-340. https://doi.org/10.5127/jep.029412.

Lommen, M. J. J., Engelhard, I. M., \& van den Hout, M. A. (2010). Neuroticism and avoidance of ambiguous stimuli: Better safe than sorry? Personality and Individual Differences, 49(8), 1001-1006. https://doi.org/10.1016/j.paid.2010.08.012.
Lonsdorf, T. B., \& Merz, C. J. (2017). More than just noise: Inter-individual differences in fear acquisition, extinction and return of fear in humans - biological, experiential, temperamental factors, and methodological pitfalls. Neuroscience \& Biobehavioral Reviews, 80, 703-728. https://doi.org/10.1016/j.neubiorev.2017.07.007.

McGaugh, J. L. (2000). Neuroscience - memory - a century of consolidation. Science, 287(5451), 248-251. https://doi.org/10.1126/science.287.5451.248.

Mertens, G., Braem, S., Kuhn, M., Lonsdorf, T. B., van den Hout, M. A., \& Engelhard, I. M. (2018). Does US expectancy mediate the additive effects of CS-US pairings on contingency instructions? Results from subjective, psychophysiological and neural measures. Behaviour Research and Therapy, 110, 41-46. https://doi.org/10.1016/j. brat.2018.09.003.

Mertens, G., Kuhn, M., Raes, A. K., Kalisch, R., De Houwer, J., \& Lonsdorf, T. B. (2016). Fear expression and return of fear following threat instruction with or without direct contingency experience. Cognition \& Emotion, 30(5), 968-984. https://doi.org/10. 1080/02699931.2015.1038219.

Milad, M. R., Orr, S. P., Pitman, R. K., \& Rauch, S. L. (2005). Context modulation of memory for fear extinction in humans. Psychophysiology, 42(4), 456-464. https://doi. org/10.1111/j.1469-8986.2005.00302.x.

Morina, N., Lancee, J., \& Arntz, A. (2017). Imagery rescripting as a clinical intervention for aversive memories: A meta-analysis. Journal of Behavior Therapy and Experimental Psychiatry, 55, 6-15. https://doi.org/10.1016/j.jbtep.2016.11.003.

Nader, K. (2003). Memory traces unbound. Trends in Neurosciences, 26(2), 65-72. https:// doi.org/10.1016/S0166-2236(02)00042-5.

Neumann, D. L., \& Waters, A. M. (2006). The use of an unpleasant sound as an unconditional stimulus in a human aversive Pavlovian conditioning procedure. Biological Psychology, 73(2), 175-185. https://doi.org/10.1016/j.biopsycho.2006.03. 004.

Ney, L. J., Wade, M., Reynolds, A., Zuj, D. V., Dymond, S., Matthews, A., et al. (2018). Critical evaluation of current data analysis strategies for psychophysiological measures of fear conditioning and extinction in humans. International Journal of Psychophysiology, 134, 95-107. https://doi.org/10.1016/j.ijpsycho.2018.10.010.

Pineles, S. L., Orr, M. R., \& Orr, S. P. (2009). An alternative scoring method for skin conductance responding in a differential fear conditioning paradigm with a longduration conditioned stimulus. Psychophysiology, 46(5), 984-995. https://doi.org/10. 1111/j.1469-8986.2009.00852.x.

Scheveneels, S., Boddez, Y., Vervliet, B., \& Hermans, D. (2016). The validity of laboratorybased treatment research: Bridging the gap between fear extinction and exposure treatment. Behaviour Research and Therapy, 86, 87-94. https://doi.org/10.1016/j. brat.2016.08.015.

Sehlmeyer, C., Schöning, S., Zwitserlood, P., Pfleiderer, B., Kircher, T., Arolt, V., et al. (2009). Human fear conditioning and extinction in neuroimaging: A systematic review. PLoS One, 4(6)https://doi.org/10.1371/journal.pone.0005865.

Shanks, D. R., \& Berry, C. J. (2012). Are there multiple memory systems? Tests of models of implicit and explicit memory. Quarterly Journal of Experimental Psychology, 65(8), 1449-1474. https://doi.org/10.1080/17470218.2012.691887.

Sjouwerman, R., Scharfenort, R., \& Lonsdorf, T. B. (2017). Individual differences in fear learning: Specificity to trait-anxiety beyond other measures of negative affect, and mediation via amygdala activation. BioRxiv, 233528. https://doi.org/10.1101/ 233528.

Soeter, M., \& Kindt, M. (2010). Dissociating response systems: Erasing fear from memory. Neurobiology of Learning and Memory, 94(1), 30-41. https://doi.org/10.1016/j.nlm. 2010.03.004.

Sperl, M. F. J., Panitz, C., Hermann, C., \& Mueller, E. M. (2016). A pragmatic comparison of noise burst and electric shock unconditioned stimuli for fear conditioning research with many trials. Psychophysiology, 53(9), 1352-1365. https://doi.org/10.1111/psyp. 12677.

Spielberger, C. D., Gorsuch, R. C., Lushene, R. E., Vagg, P. R., \& Jacobs, G. A. (1983). Manual for the state-trait anxiety inventory. Palo Alto: Consulting Psychologists Press.

Torrents-Rodas, D., Fullana, M. A., Bonillo, A., Caseras, X., Andión, O., \& Torrubia, R. (2013). No effect of trait anxiety on differential fear conditioning or fear generalization. Biological Psychology, 92(2), 185-190. https://doi.org/10.1016/j.biopsycho. 2012.10.006.

Vervliet, B., Baeyens, F., Van den Bergh, O., \& Hermans, D. (2013). Extinction, generalization, and return of fear: A critical review of renewal research in humans. Biological Psychology, 92(1), 51-58. https://doi.org/10.1016/j.biopsycho.2012.01.006.

Vervliet, B., Craske, M. G., \& Hermans, D. (2013). Fear extinction and relapse: State of the art. Annual Review of Clinical Psychology, 9, 215-248. https://doi.org/10.1146/ annurev-clinpsy-050212-185542.

Wegerer, M., Blechert, J., Kerschbaum, H., \& Wilhelm, F. H. (2013). Relationship between fear conditionability and aversive memories: Evidence from a novel conditioned-intrusion paradigm. PLoS One, 8(11)https://doi.org/10.1371/journal.pone.0079025. 